\title{
Trans-equatorial migration and mixing in the wintering areas of a pelagic seabird
}

\author{
Jacob González-Solís ${ }^{1,2 *}$, John P Croxall ${ }^{2,3}$, Daniel Oro ${ }^{4}$, and Xavier Ruiz ${ }^{1}$
}

Despite increasing interest in long-distance migration, the wintering areas, migration corridors, and population mix in winter quarters of most pelagic marine predators are unknown. Here, we present the first study tracking migration movements of shearwaters through the non-breeding period. We used geolocators (global location sensing [GLS] units based on ambient light levels) to track 22 Cory's shearwaters (Calonectris diomedea) breeding in three different areas. Most birds wintered in one or more of three relatively small areas, all clearly associated with major coastal upwelling systems of the tropical and south Atlantic. Trans-equatorial movements were dominated by prevailing trade winds and westerlies, while calm, oligotrophic areas were avoided. Breeding populations clearly differed in their preference amongst the three major wintering areas, but showed substantial mixing. This illustrates the exceptional value of GLS, not only for determining and describing the influence of oceanographic features on migration patterns, but also for assessing population mix in winter quarters. This knowledge is essential to understanding the impacts of population-level threats, such as longlining, offshore windfarms, and oil spills on multiple breeding sites, and will be critical in devising conservation policies that guarantee the sustainable exploitation of the oceans.

Front Ecol Environ 2007; 5(6): 297-301

$\mathrm{P}$ elagic marine predators, such as some fishes, cetaceans, and seabirds, complete long-distance migrations of several thousands of kilometers. Despite intense research interest in migration in recent decades, the main patterns and processes governing long-distance movements of seabirds are essentially unknown. Seabirds are thought to respond to wind direction and strength, as well as to biological and physical features of sea-surface waters (Shealer 2002). However, much of the evidence for this is based on observation (from ship-based surveys) of birds of unknown origin and breeding status. Knowing how seabirds use space at individual and population levels is necessary if we are to understand the functioning of marine systems, particularly the interactions between the large-scale spatial dynamics of marine predators and lower trophic levels. Such information is also vital for studying the evolution of migratory routes, migratory connectivity at wintering areas, and metapopulation dynamics (Alerstam 1990). It is also essential for management and conservation purposes, given that many seabird species are endangered by spatially explicit threats, such as longline fisheries, oil spills, and offshore wind farms (Brooke 2004).

Traditional approaches, such as large-scale banding programs, cannot fully reveal patterns of seabird migratory movements due to the difficulty of recapture on the open

${ }^{1}$ Departament de Biologia Animal (Vertebrats), Universitat de Barcelona, Barcelona 08028, Spain *(jgsolis@ub.edu); ㄹitish Antarctic Survey, Natural Environment Research Council, Cambridge CB3 OET, UK; ${ }^{3}$ current address: BirdLife International, Cambridge CB3 ONA, UK; ${ }^{4}$ Instituto Mediterráneo de Estudios Avanzados, Mallorca, Spain

ocean. More recent developments, such as satellite tracking, have limitations connected with instrument size and mass, battery life, and particularly with attachment methods for seabirds. Nevertheless, new miniature geolocators, known as global location sensing (GLS) units, can be attached to a band for several years and will record two positions per day (Afanasyev 2004). Because their cost is modest, extensive deployment programs can be developed, providing for a broader overview of migration behavior and habitat use. Tracking of migrating animals using geolocators has mainly been explored for large seabird species, such as albatrosses, in the Southern Ocean (BirdLife International 2004; Croxall et al. 2005). Although the main migratory movements and wintering areas of many seabirds are relatively well known, current information for the Atlantic and Pacific is almost entirely based on observations at sea and a few bird recoveries (Brooke 2004). Very recently, however, a study on sooty shearwater (Puffinus griseus) in the Pacific also showed that geolocators are a useful tool for describing general patterns of long-distance migration in mediumsized seabirds (Shaffer et al. 2006).

In this study, we identify the complex migration patterns of three populations of Cory's shearwaters (Calonectris diomedea; Figure 1) breeding in the northeast Atlantic and Mediterranean and mixing in one or more of three specific areas of the tropical and south Atlantic during winter. This species is secretive, nesting in burrows on islets that are difficult to access and using the colonies only during darkness to minimize potential predation. Although not currently endangered, they are increasingly threatened, particularly by the expansion of longline fisheries (Cooper et al. 2003). Recoveries and ship observa- 


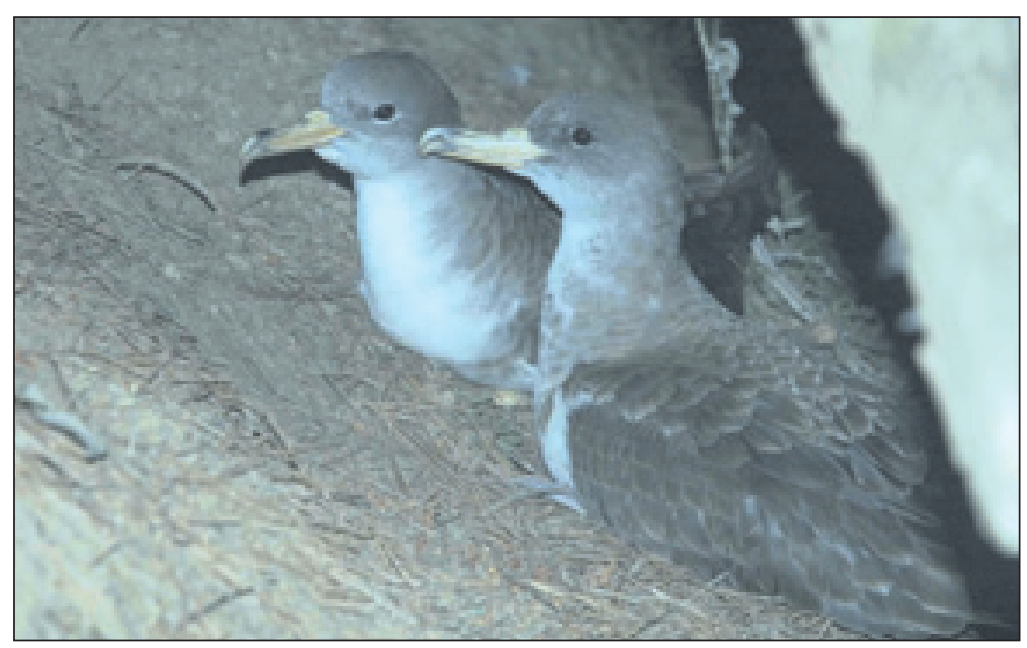

Figure 1. Male and female Cory's shearwaters (Calonectris diomedea). ing shearwaters and to help identify the main priorities for their conservation.

\section{Methods}

We deployed leg-mounted 10-g geolocators (Figure 3) on Cory's shearwaters breeding in three geographically distinct areas: the Azores Islands, the Canary Islands, and the Mediterranean. A preliminary deployment at Chafarinas Island (Mediterranean) in June 2000 yielded data from two geolocators in June 2001. In June and July 2002, we deployed a total of 50 geolocators at Vila Islet (Azores), Veneguera (Gran Canaria, Canary Islands), and Pantaleu Islet (Balearic Island, Mediterranean). After approximately 1 year, we recovered complete data from eight, seven, and five geolocators from these three sites, respectively. Deployment of these geolocators on Cory's shearwaters has no detectable short-term effect on the birds (Igual et al. 2005). Positioning and filtering procedures are explained in WebPanel 1.

To test for an association between wintering areas and marine productivity, we first calculated the mean chlorophyll-a concentration of each $200 \times 200-\mathrm{km}$ square in January 2003, within a grid representing the area potentially occupied by the wintering birds. This area was defined as the Atlantic portion within the maximum and minimum latitude and longitude occupied by the instrumented Cory's shearwaters over the study period (between -57 and 45 degrees longitude and -44 and 29 degrees latitude, comprising 1250 chlorophyll-a concentration values). The marine productivity of the wintering area of the 20 birds we studied in 2002-2003 was obtained by averaging the chlorophyll-a concentration of the $200 \times 200 \mathrm{~km}$ squares beneath the positions obtained in January, when all birds were wintering. Assuming any area was equally suitable for wintering, we obtained an empirical distribution function by 10000 re-samplings of 20 random chlorophyll-a concentration values from the 1250 potentially occupied. Significance of the association between chlorophyll-a concentration values and the location of the wintering areas was tested by calculating the two-tailed probability in the obtained empirical distribution defined by the mean value of all the birds. Chlorophyll-a concentrations were obtained from the SeaWiFS project (http://ocean color.gsfc.nasa.gov/SeaWiFS/).

\section{Results}

Migrating birds traveled a minimum distance of 15000 to $35000 \mathrm{~km}$ between two consecutive breeding seasons. In all cases, pelagic movements were easily divided into frequent foraging trips around the breeding areas, rapid, long-distance migrations, and smaller-scale movements within
Figure 2. Cory's shearwaters near a colony at the Chafarinas Islands in the Mediterranean Sea. 
a well defined wintering ground. Most birds wintered in three main areas, associated with the Benguela and Agulhas Currents, the Brazilian Current, and the Canary Current, but the proportion of birds that wintered in each area differed significantly among the three breeding populations $(\mathrm{G}=11.26, \mathrm{df}=4$, $P=0.02)$. That is, five out of eight birds from the Azores (62\%), four out of seven from the Canaries (57\%), and two out of seven from the Mediterranean (29\%) used the Benguela Current area extending to the Agulhas Current (Figure 4a). Three birds from the Azores (37\%) and one from the Canaries (14\%) used the Brazilian current (Figure 4b). In contrast, four Mediterranean birds (57\%) and one bird from the Canaries (14\%) wintered in association with the Canary Current off the coasts of the Western Sahara and Senegal (Figure 4c). Secondary wintering areas were located in the oceanic central South Atlantic and tropical East Atlantic (one bird each, also depicted in Figures 4a and $4 \mathrm{c}$, respectively). The three main wintering areas overlapped with areas characterized by high chlorophyll-a concentrations $(P<0.01)$. Birds spent an average of 19 days ( $\mathrm{sd}=10$ days; range $3-40$ days) traveling to the wintering areas, 80 days within these areas $(\mathrm{sd}=17$ days; range 49-106 days), and 23 days traveling back to the breeding areas ( $\mathrm{sd}=7$ days; range $10-37$ days).

Migration routes to the eastern South Atlantic and to the secondary area in the central South Atlantic were counter-clockwise around the South Atlantic gyre, with more indefinite clockwise movements around the North Atlantic gyre (Figure 4a). Only one migrant out of 12 traveled against trade winds through the eastern Atlantic to reach the Benguela Current (depicted in yellow in Figure 4a). Birds migrating to the western South Atlantic followed the coast and returned through a more easterly corridor (Figure 4b). Migration routes of birds wintering in the northeast tropical Atlantic showed clockwise movements in their return to the breeding colonies (Figure 4c).

\section{Discussion}

We provide the first year-round tracking study describing the wintering grounds and migratory routes for different populations of a marine migrant. Though birds range through much of the Atlantic Ocean, the actual wintering areas that sustain most of the world population of this species are restricted to four specific, oceanographically defined areas (Figure 4). These are the Benguela and Agulhas Currents, the southern part of the Brazil Current, and the Canary Current. All of these Atlantic coastal biomes are associated with major upwelling phenomena, showing high chlorophyll-a concentrations and high rates of primary production (Longhurst 1998), and thus sustaining abundant food for seabirds. To reach these areas,

seabirds followed relatively narrow migration corridors in both the North and South Atlantic. Recent results from the Pacific Ocean for a related seabird, the sooty shearwater (Puffinus griseus), closely mirror our findings (Shaffer et al. 2006). Although this species breeds in the Southern Hemisphere, its trans-equatorial migration to productive North Pacific areas suggests analogous patterns and drivers.

It has long been suspected that many seabird species use winds to facilitate their trans-equatorial movements (Alerstam 1990). Prevailing winds in the Atlantic circulate clockwise in the Northern Hemisphere and counterclockwise in the Southern Hemisphere, which had led some workers to hypothesize a figure-eight migration pattern for several shearwater species (Alerstam 1990; Brooke 2004). In general, our results, together with those of Schaffer et al. (2006), corroborate this hypothesis and provide further evidence that shearwaters travel with prevailing winds, thereby saving a substantial amount of energy (Liechti and Brudurer 1998; Weimerskirch et al. 2000). This pattern is particularly apparent in the Southern Hemisphere, where 11 out of 12 Cory's shearwaters traveling to and from the southeastern Atlantic followed the counter-clockwise Atlantic gyre (Figure 4a). However, on several occasions, birds did not follow the gyres, but shifted their route a few hundred kilometers to avoid flying into tradewinds; for example, the four birds returning from the southwestern Atlantic used a more easterly corridor instead of returning along their outgoing coastal path (Figure 4b).

This study confirms that the Canary Current area is one of the primary wintering areas for Cory's shearwaters (Ristow et al. 2000), but, contrary to previous suggestions, the wintering areas of the Mediterranean and Atlantic subspecies of Cory's shearwater are not geographically exclusive. Indeed, the rates of mixing of birds from different breeding populations at the three discrete wintering areas suggest considerable migratory connectivity among breeding populations. Although evidence of pairing behav- 

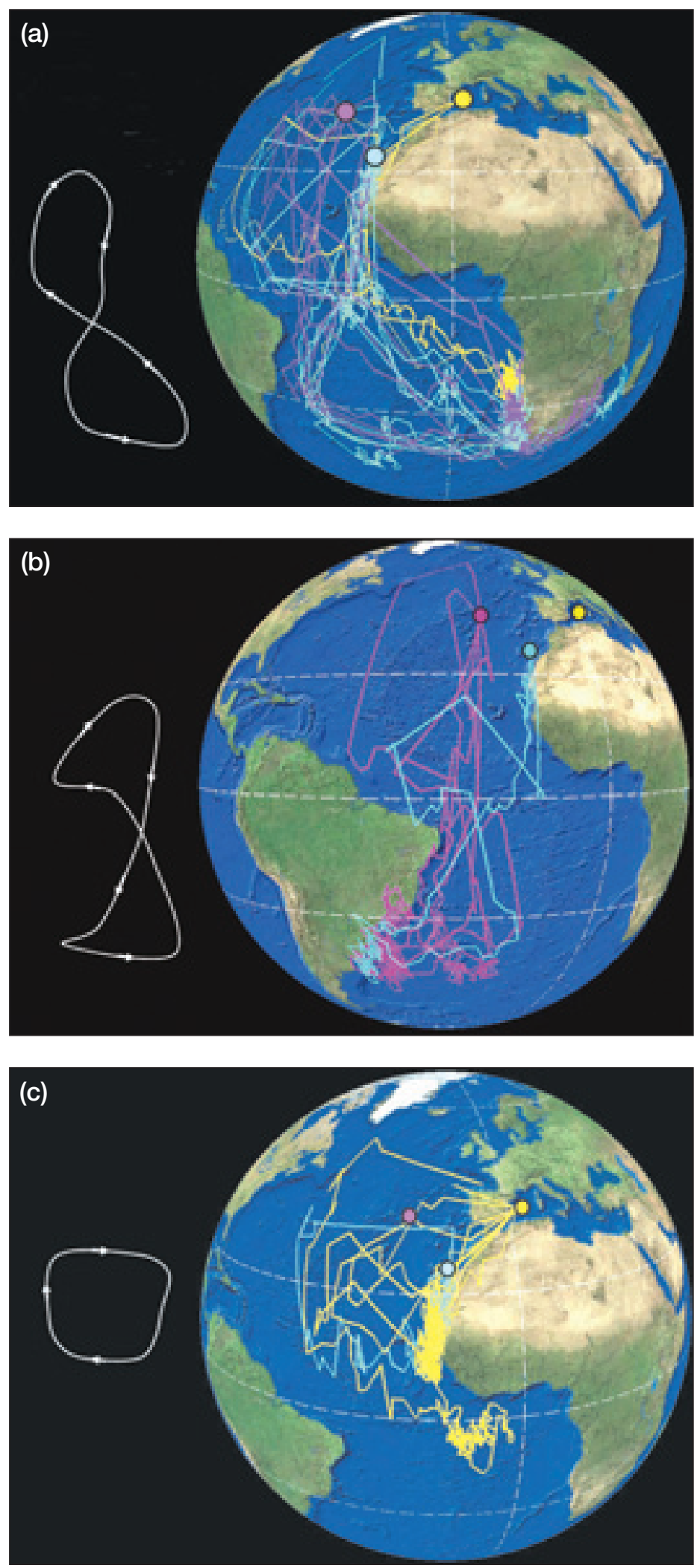

ior away from the breeding site is lacking, mixing may promote migratory connectivity, because many shearwaters migrate in flocks and some birds, in particular less experienced pre-breeders, may simply follow birds from other colonies to return to their breeding grounds. Thus, our results suggest a potential for dispersal and, ultimately, gene
Figure 4. Each line corresponds to the annual migration of one shearwater and colors refer to the population of origin ( magenta $=$ Azores; blue $=$ Canary $;$ yellow = Mediter ranean). A general-zed migration model (white solid line) indicates the approximate route and the direction of most birds in each panel. Dashed lines indicate Equator, Tropics of Cancer and Capricorn, and Greenwich meridian. Note that all tracks over land result from inaccuracies in the GLS method. (a) Migration routes of 11 Cory's shearwaters breeding in the Canary Islands (four), the Azores (five), and Mediterranean islands (two), and wintering in the eastern South Atlantic (assoicated with the Benguela Current) and the western Indian Ocean (associated with the Agulhas Currents). Also shown is one bird from the Canary Islands wintering in the central South Atlantic. Only one bird (thick yellow line) traveled to the wintering area through the eastern Atlantic and against the prevailing winds. (b) Migration routes of four Cory's shearwaters breeding in the Canary Islands (one) and Azores Islands (four) and wintering in the western South Atlantic associated with the Brazilian Current. (c) Migration routes of five Cory's shearwaters breeding in the Canary Islands (one) and Mediterranean islands (four) and wintering in the northeast tropical Atlantic associated with the Canary Current. Also shown is one bird from the Mediterranean wintering in the east tropical Atlantic.

flow among breeding populations. This underlines the need for new studies (including genetic studies) of the taxonomy and metapopulation structure of this species (Gómez-Díaz et al. 2006).

Mixing of populations in winter quarters may also have important implications in terms of exposure of multiple populations to identical sources of mortality, such as longlining, offshore windfarms, oil spills, and other sources of pollutants. Although Cory's shearwater is a relatively abundant species, with a current global conservation status of "least concern", known and potentially adverse interactions with fisheries, especially longline fisheries, in Mediterranean and North Atlantic waters have recently raised concern (Cooper et al. 2003). However, the apparently vast wintering range in the Southern Hemisphere and limited number of reports of incidental mortality in major longline fisheries in this region suggest that the risk in wintering areas may not yet be as serious as in breeding areas.

Our results show that birds spend on average 80 days in their wintering areas, plus 19 and 23 days, respectively, flying to and from these areas; overall, this represents a substantial proportion of their annual cycle. Two of the main Cory's shearwater populations generally winter in the southern Brazilian and Benguela Current, together with a substantial proportion of the Mediterranean Cory's shearwater population (29\%). These are also key wintering areas for many albatross and petrel species, most of which are now globally threatened (BirdLife International 2004; Phillips et al. 2006). These areas are known for high longlining effort and high bycatch 
rates of procellariiform seabirds (Tuck et al. 2003) and also for considerable risk of incidental mortality in trawl fisheries, data that are only just becoming available. Therefore, our findings highlight the urgent need for reliable data on bycatch rates in the Atlantic and the Mediterranean and the development of reliable methods for determining seabirds' population of origin, in order to assess the impact of longlining and other threats on breeding populations (Gómez-Díaz and González-Solís in press). In addition, we show that geolocation studies can reveal the spatiotemporal distribution of seabirds, even in remote areas outside the breeding season, which is essential for defining critical habitat for birds at sea. Ultimately, however, the impact of potential population-level threats during the non-breeding period needs to be evaluated on the breeding grounds, by monitoring seabird numbers and conducting supporting studies on population dynamics. If adverse population trends are detected at breeding colonies, Cory's shearwaters are likely to merit globally threatened vulnerable status, which would add pressure for the adoption of appropriate mitigation measures in the many major fisheries of the Benguela and Brazil Current marine systems. In fact, Mediterranean Cory's shearwaters are currently considered endangered in Spain (Madroño et al. 2004) and high adult mortalities have been detected in some breeding colonies (D Oro unpublished).

This study illustrates that spatiotemporal distributions and migration patterns of medium-sized seabirds can be successfully studied throughout the entire year using geolocators. This technique opens new possibilities for studying the critical periods in the annual cycle of endangered seabirds and potential threats at sea. Our results show that migration strategies and the location of wintering grounds may differ greatly, depending on the population of origin. Also, we show for the first time the extent to which different populations can mix in specific and restricted wintering areas. Such mixing can have important consequences for the exposure of different populations to the same threat. Our results also help to define key marine habitats for birds and highlight the critical importance of taking into account migration routes and wintering areas in considering mortality risks posed by longline fisheries and other emerging threats.

\section{Acknowledgements}

We thank the SeaWiFS project for providing data on chlorophyll concentrations, V Afanasyev and D Briggs for providing geolocators, E Gómez-Díaz, J Navarro, V Neves, J Bried, MG Forero, M Igual, I Afan, and L Llorens for help in the field, and P Calabuig, Consejeria de Medio Ambiente del Cabildo de Gran Canaria, Dirección General de Política Ambiental del Gobierno de Canarias, Secretaria Regional do Ambiente da Região Autónoma dos Açores, and Govern Balear for support. JG-S was supported by a reincorporation grant from the Generalitat de Catalunya, by a contract of the Program
Ramón y Cajal of the Ministerio de Ciencia y Tecnología (MCyT) of Spain, and by Fondos FEDER during analysis and writing. Additional financial support was provided by the projects REN2002-01164/GLO, BOS2003-01960, and BOS2000-0569-CO2-01 from MCyT, from the Fundación Banco Bilbao Vizcaya Argentaria, and 2001SGR 00091 from the Generalitat de Catalunya.

\section{References}

Afanasyev V. 2004. A miniature daylight level and activity data recorder for tracking animals over long periods. Mem Nat Inst Pol Res Special Issue 58: 227-33.

Alerstam T. 1990. Bird migration. Cambridge, UK: Cambridge University Press.

BirdLife International. 2004. Tracking ocean wanderers: the global distribution of albatrosses and petrels. Results from the Global Procellariiform Tracking Workshop; 2003 Sept 1-5; Gordon's Bay, South Africa. Cambridge, UK: BirdLife International.

Brooke M. 2004. Albatrosses and petrels across the world. Oxford, UK: Oxford University Press.

Camphuysen CJ and Van Der Meer J. 2001. Pelagic distribution, moult and (sub-) specific status of Cory's shearwaters Calonectris /d/ diomedeal borealis wintering off southern Africa. Mar Ornithol 29: 89-96.

Cooper J, Baccetti N, Belda EJ, et al. 2003. Seabird mortality from longline fishing in the Mediterranean Sea and Macaronesian waters: a review and a way forward. Sci Mar 67: 57-64.

Croxall JP, Silk JRD, Phillips RA, et al. 2005. Global circumnavigations: tracking year-round ranges of nonbreeding albatrosses. Science 307: 249-50.

Gómez-Díaz E and González-Solís J. Geographic assignment of seabirds to the origin: combining morphologic, genetic, and biogeochemical analyses. Ecol Appl. In press.

Gómez-Díaz E, González-Solís J, Peinado MA, et al. 2006. Phylogeography of Calonectris shearwaters using molecular and morphometric data. Mol Phyl Evol 41: 322-32.

Igual JM, Forero MG, Tavecchia G, et al. 2005. Short-term effects of data-loggers on Cory's shearwater (Calonectris diomedea). Mar Biol 146: 619-24.

Liechti F and Brudurer B. 1998. The relevance of wind for optimal migration theory. J Avian Biol 29: 561-68.

Longhurst A. 1998. Ecological geography of the sea. San Diego, CA: Academic Press.

Madroño A, Gonzalez C, and Atienza JC. 2004. Libro rojo de las aves de España. Madrid, Spain: Dirección General de la Biodiversidad-SEO/BirdLife.

Phillips RA, Silk JRD, Croxall JP, et al. 2006. Year-round distribution of white-chinned petrels from South Georgia: relationships with oceanography and fisheries. Biol Conserv 129: 336-47.

Ristow D, Berthold P, Hashmi D, et al. 2000. Satellite tracking of Cory's shearwater migration. Condor 102: 696-99.

Shaffer SA, Tremblay Y, Weimerskirch H, et al. 2006. Migratory shearwaters integrate oceanic resources across the Pacific Ocean in an endless summer. P Natl Acad Sci USA 103: 12799-12802.

Shealer DA. 2002. Foraging behavior and food of seabirds. In: Schreiber EA and Burger J (Eds). Biology of marine birds. Boca Raton, FL: CRC Press.

Thibault JC, Bretagnolle V, and Rabouam C. 1997. Cory's shearwater. BWP Update 1: 75-98.

Tuck GN, Polacheck T, and Bulman CM. 2003. Spatio-temporal trends of longline fishing effort in the Southern Ocean and implications for seabird bycatch. Biol Conserv 114: 1-27.

Weimerskirch H, Guionnet T, Martin J, et al. 2000. Fast and fuel efficient? Optimal use of wind by flying albatrosses. P Roy Soc Lond B Bio 267: 1869-74. 